\title{
PENGARUH PERKUATAN PELAT CFRP TERHADAP PERILAKU TULANGAN TARIK STRUKTUR BALOK BETON BERTULANG
}

\author{
Elfania Bastian ${ }^{1}$, Rendy Thamrin ${ }^{2}$, dan Jafril Tanjung ${ }^{3}$
}

\begin{abstract}
ABSTRAK
Dalam studi ini dilakukan analisis numerik tentang pengaruh perkuatan dengan pelat CFRP (Carbon Fiber Reinforced Polymer) terhadap tegangan tulangan tarik. Tegangan pada tulangan tarik ditinjau pada daerah sekitar perletakan balok sederhana dengan dua tumpuan. Untuk maksud tersebut serangkaian model numerik dipersiapkan dengan jenis tulangan yang berbeda. Dimana panjang penyaluran tambahan divariasikan $100 \mathrm{~mm}$ dan $250 \mathrm{~mm}$. Tulangan yang digunakan adalah tulangan baja dan GFRP (Glass Fiber Reinforced Polymer). Hasil analisis menjelaskan bahwa perkuatan dengan pelat CFRP dapat meningkatkan kapasitas balok dimana tegangan yang diterima oleh tulangan tarik menurun. Disamping itu tulangan tarik GFRP juga terbukti efektif meningkatkan daktilitas balok beton bertulang.
\end{abstract}

Kata kunci : Metode Elemen Hingga, ATENA, Perkuatan pelat CFRP, Tulangan GFRP, Uji balok beton bertulang

\section{PENDAhuluan}

Perkembangan teknologi beton pada saat sekarang ini, membuat konstruksi beton semakin banyak dipilih sebagai suatu bahan konstruksi. Konstruksi dari beton banyak memiliki keuntungan selain bahannya sangat mudah diperoleh, juga harganya relatif lebih murah, mempunyai kekuatan tekan tinggi, mudah dalam pengangkutan dan pembentukannya, serta mudah dalam hal perawatannya. Namun, beton mempunyai perilaku yang spesifik yaitu memiliki kuat tarik yang jauh lebih kecil dari kuat tekannya. Oleh karena itu material beton umumnya digabungkan dengan material lain yang mempunyai kuat tarik besar, seperti baja tulangan atau baja profil sehingga merupakan kesatuan struktur komposit yang disebut beton bertulang (Sambowo,2010).

Balok beton bertulang didesain untuk mampu memikul beban yang bekerja. Inovasi dalam desain untuk meningkatkan kinerja balok beton bertulang, salah satunya adalah dengan penambahan perkuatan eksternal menggunakan pelat CFRP. Banyak penelitian telah dilakukan untuk melihat efek dari perkuatan dengan pelat diantaranya Larralde (1992), Teng (2001), Fooster (2005), Thamrin (2003). Penelitian-penelitian tersebut di atas umumnya dilakukan untuk mengetahui pengaruh perkuatan terhadap kapasitas lentur balok. Sementara itu, pengaruh perkuatan dengan pelat CFRP terhadap tegangan tulangan tarik belum diketahui secara detail. Pada studi ini tinjauan berupa studi numerik dilakukan untuk mengetahui pengaruh perkuatan pelat CFRP terhadap tegangan tulangan tarik balok beton bertulang.

\footnotetext{
${ }^{I}$ Mahasiswa Pascasarjana Jurusan Teknik Sipil Fakultas Teknik Universitas Andalas, Staf Pengajar Universitas Muhammadiayah Sumatera Barat elfania_bastian@ymail.com

${ }^{2}$ Staf Pengajar Jurusan Teknik Sipil Fakultas Teknik Universitas Andalas, rendy@ft.unand.ac.id

${ }^{3}$ Staf Pengajar Jurusan Teknik Sipil Fakultas Teknik Universitas Andalas, jafriltanjung@ft.unand.ac.id
} 
Untuk maksud tersebut, dalam studi ini dipersiapkan model numerik balok beton bertulang dengan jenis tulangan berbeda yaitu dengan tulang baja dan tulangan GFRP. Dimana panjang penyaluran tambahan divariasikan sepanjang $100 \mathrm{~mm}$ dan $250 \mathrm{~mm}$.

\section{MODEL NUMERIK}

Analisis numerik dilakukan dengan bantuan perangkat lunak komputer berbasis metode elemen hingga ATENA (Cervenka, 2011). Disamping itu juga digunakan perangkat lunak komputer berbasis analisis penampang RCCSA (Thamrin, 2014). Model yang digunakan adalah balok beton bertulang dimana perbandingan a/d sebesar 2.19. Dimana a merupakan panjang bentang geser dan $\mathrm{d}$ merupakan tinggi efektif penampang balok. Balok beton bertulang yang dianalisis mempunyai panjang $2500 \mathrm{~mm}$ yang terletak pada dua tumpuan dengan dua pembebanan simetris, seperti diperlihatkan dalam Gambar 1(a). Penampang balok mempunyai dimensi lebar (b) $250 \mathrm{~mm}$, tinggi (h) $500 \mathrm{~mm}$ dengan tulangan rangkap, seperti diperlihatkan dalam Gambar 1(b). Detail model numerik ditabulasikan dalam Tabel 1.

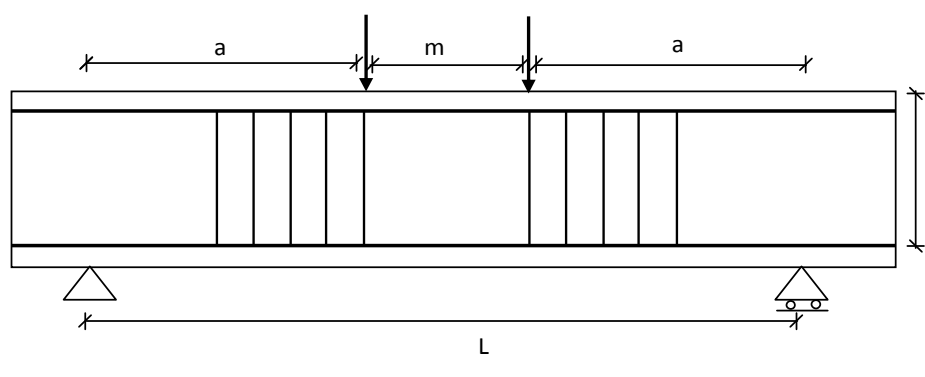

(a)

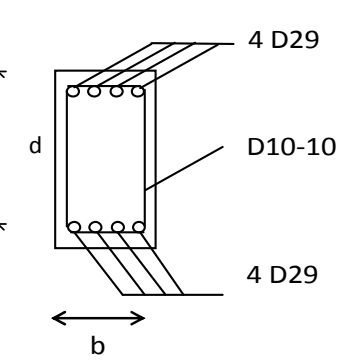

(b)

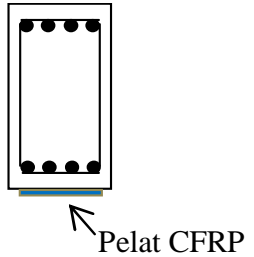

(c)

Gambar 1. Balok beton bertulang untuk pengujian

Tabel 1. Ukuran Detail Model

\begin{tabular}{lllll}
\hline Uraian & Notasi & Satuan & Besar \\
\hline Panjang Balok & $\mathrm{L}$ & $\mathrm{mm}$ & 2500 \\
Lebar Balok & $\mathrm{b}$ & $\mathrm{mm}$ & 250 \\
Tinggi Balok & $\mathrm{h}$ & $\mathrm{mm}$ & 500 \\
Tinggi efektif & $\mathrm{d}$ & $\mathrm{mm}$ & 455.5 \\
Panjang Bentang Geser & $\mathrm{a}$ & $\mathrm{mm}$ & 1000 \\
Jarak Antar Beban & $\mathrm{m}$ & $\mathrm{mm}$ & 500 \\
\hline
\end{tabular}

Balok mempunyai 4 tulangan tarik ulir diameter $29 \mathrm{~mm}$ dan 4 tulangan tekan ulir diameter $29 \mathrm{~mm}$ serta tulangan geser berupa tulangan polos dengan diameter $10 \mathrm{~mm}$. Pada balok yang diberi perkuatan berupa pelat CFRP dipasang secara eksternal pada permukaan bagian bawah balok. Pelat CFRP yang digunakan memiliki lebar $200 \mathrm{~mm}$ yang terdiri atas 2 pelat CFRP lebar $100 \mathrm{~mm}$, tebal $1.4 \mathrm{~mm}$, dan dipasang sepanjang balok seperti diperlihatkan pada Gambar 1c.

Karena balok yang digunakan merupakan balok simetris, permodelan pada ATENA hanya menggunakan setengah bentang balok dimana pada bagian balok yang terpotong diberi tumpuan rol seperti diperlihatkan dalam Gambar 2(a). Model elemen hingga terdiri atas 87 isotropik kuadrat elemen. Pada bagian tumpuan dan beban diberi plat dengan asumsi material plan stress isotropic (Cervenka, 2011). Pada node ditengah plat tumpuan diberi tumpuan berupa tumpuan sendi, sedangkan monotoring point diletakkan pada node ditengah beban dan pada node pinggir balok seperti diperlihatkan pada Gambar 2(b). Hal ini dimaksudkan untuk mengetahui pertambahan beban dan deformasi pada balok. 


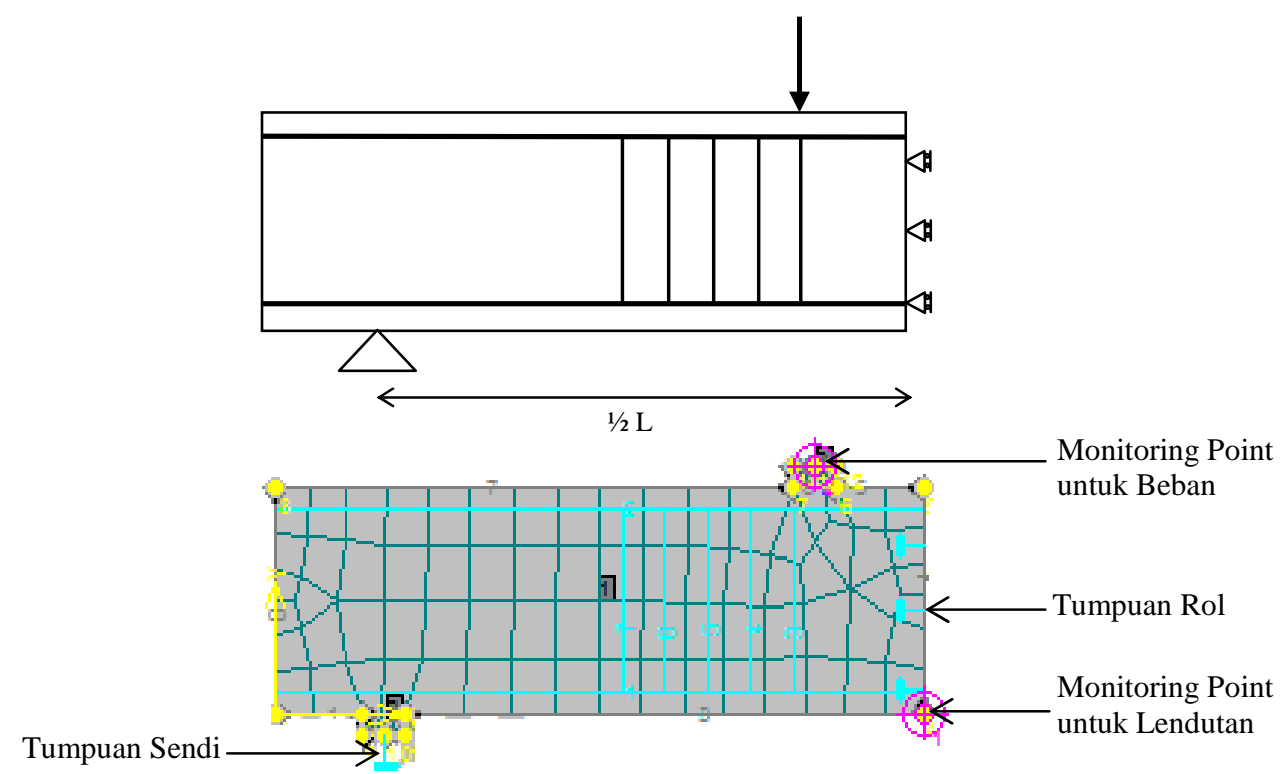

Gambar 2. Jaring Elemen Hingga

Propertis material yang digunakan dalam model numerik ditabulasi dalam Tabel 2 untuk maetrial beton dan Tabel 3 untuk material baja tulangan, sedangkan untuk material GFRP dan CFRP ditabulasikan dalam Tabel 4 dan Tabel 5. Besarnya nilai material propertis dalam studi ini diambil dai beberapa sumber referensi yaitu Cervenka (2011), http://www.krakatauwajatama.co.id, SJ.Fooster (2005) dan ACI 440.1R-06.

Nonelinieritas beton dimodelkan mengikuti permodelan konstitutif SBETA, sedangkan tulangan baja mengikuti model Biniliner With Hardening (Cervenka, 2011). Untuk tulangan GFRP dan pelat CFRP diasumsikan dapat mengeikuti model konstitutif Biliniear With Hardening yang digunakan dalam perangkan lunak ATENA.

Tabel 2. Propertis material beton

\begin{tabular}{l|l|l|l}
\hline Propertis & Notasi & Satuan & Besar \\
\hline Modulus Elastisitas & $\mathrm{Ec}$ & $\mathrm{MPa}$ & $3.03 \times 10^{4}$ \\
Poisson'is Ratio & $\mu$ & - & 0.02 \\
Tegangan Tarik & $\mathrm{f}_{\mathrm{t}}$ & $\mathrm{MPa}$ & 2.582 \\
Tegangan Tekan & $\mathrm{f}_{\mathrm{c}}$ & $\mathrm{MPa}$ & 30 \\
\hline
\end{tabular}

Tabel 3. Propertis material tulangan baja

\begin{tabular}{l|l|l|l}
\hline Propertis & Notasi & Satuan & Besar \\
\hline Modulus Elastisitas & $\mathrm{E}$ & $\mathrm{MPa}$ & $2 \times 10^{5}$ \\
Regangan & $\varepsilon_{\lim }$ & - & 0.05 \\
Tegangan Yield & $\sigma_{\mathrm{y}}$ & $\mathrm{MPa}$ & 500 \\
Tegangan Ultimate & $\sigma_{\mathrm{t}}$ & $\mathrm{MPa}$ & 630 \\
\hline
\end{tabular}

Tabel 4. Propertis material tulangan GFRP

\begin{tabular}{l|l|l|l}
\hline Propertis & Notasi & Satuan & Besar \\
\hline Modulus Elastisitas & $\mathrm{E}$ & $\mathrm{MPa}$ & $5.15 \times 10^{4}$ \\
Regangan & $\varepsilon_{\lim }$ & - & 0.02 \\
Tegangan Yield & $\sigma_{\mathrm{y}}$ & $\mathrm{MPa}$ & 769.4 \\
Tegangan Ultimate & $\sigma_{\mathrm{t}}$ & $\mathrm{MPa}$ & 769.4 \\
\hline
\end{tabular}


Tabel 5. Propertis material pelat CFRP

\begin{tabular}{lllll}
\hline Propertis & Notasi & Satuan & Besar \\
\hline Modulus Elastisitas & $\mathrm{E}$ & $\mathrm{MPa}$ & $1.6 \times 10^{5}$ \\
Regangan & $\varepsilon_{\lim }$ & - & 0.02 \\
Tegangan Yield & $\sigma_{\mathrm{y}}$ & $\mathrm{MPa}$ & 2150 \\
Tegangan Ultimate & $\sigma_{\mathrm{t}}$ & $\mathrm{MPa}$ & 2150 \\
\hline
\end{tabular}

Dalam studi ini dianalisis 8 model numerik diamana jenis tulangan tarik, panjang penyaluran tambahan merupakan parameter studi. Penamaan model numerik yang dimodelkan dirangkum dalam Tabel.6.

Tabel 6. Variasi Model Numerik

\begin{tabular}{l|l|l|l}
\hline Uraian & Jenis Tulangan & $\begin{array}{c}\text { Panjang Penyaluran } \\
\text { Tambahan }\end{array}$ & Kode Model \\
\hline Tanpa Perkuatan & Baja & $100 \mathrm{~mm}$ & PSW-1N \\
Tanpa Perkuatan & Baja & $250 \mathrm{~mm}$ & PSW-2N \\
Tanpa Perkuatan & GFRP & $100 \mathrm{~mm}$ & PGW-1N \\
Tanpa Perkuatan & GFRP & $250 \mathrm{~mm}$ & PGW-2N \\
Dengan Perkuatan & Baja & $100 \mathrm{~mm}$ & PSW-1C \\
Dengan Perkuatan & Baja & $250 \mathrm{~mm}$ & PSW-2C \\
Dengan Perkuatan & GFRP & $100 \mathrm{~mm}$ & PGW-1C \\
Dengan Perkuatan & GFRP & $250 \mathrm{~mm}$ & PGW-2C \\
\hline
\end{tabular}

\section{HASIL DAN PEMBAHASAN}

Setelah dilakukan analisis secara numerik, diketahui bahwa penambahan plat CFRP pada daerah tarik balok beton bertulang, dapat menambah kemampuan menahan beban dari balok tersebut dan juga dapat mengurangi tegangan pada daerah perletakan. Pada Gambar 3.(a) terlihat bahwa CFRP memiliki konstribusi untuk meningkatkan kemampuan balok beton bertulang dengan tulangan baja dalam menahan beban sebesar $8,4 \%$. Hal ini membuktikan pada balok dengan gaya geser dominan, pelat CFRP tetap memberi konstribusi menahan beban.

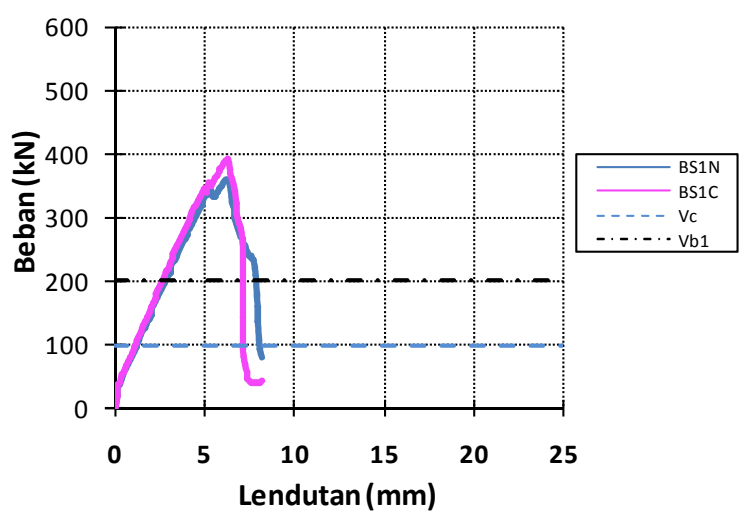

(a)

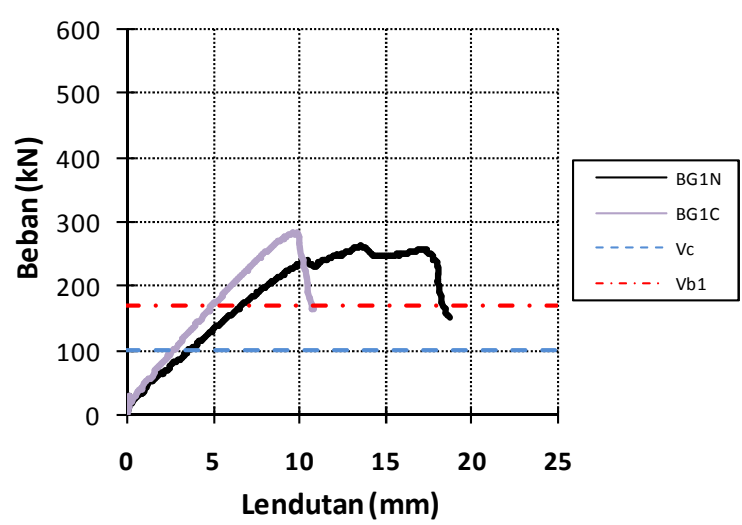

(b)

Gambar 3. Pengaruh Penambahan Pelat CFRP Terhadap Kapasitas Balok

Selanjutnya analisis pada balok dengan tulangan GFRP yang diperkuat dengan pelat CFRP menunjukkan bahwa, pelat CFRP masih berkonstribusi dengan baik pada balok dengan deformasi besar. Hal ini dibuktikan dengan bertambahnya kapasitas balok sebesar $7.8 \%$ seperti terlihat pada Gambar 3.(b).

Analisis ini dilakukan dengan menggunakan variasi jenis tulangan, yaitu tulangan baja dan tulangan GFRP. Tulangan GFRP seperti yang terlihat pada Tabel 5 memiliki nilai elastisitas yang 
jauh lebih rendah jika dibandingkan elastisitas tulangan baja (Tabel 4). Elastisitas ini berpengaruh terhadap deformasi balok. Pada Gambar 4 terlihat bahwa balok dengan tulangan GFRP memiliki deformasi yang lebih besar. Hal ini memperlihatkan bahwa tulangan dengan GFRP mampu menambah daktilitas dari balok beton bertulang.

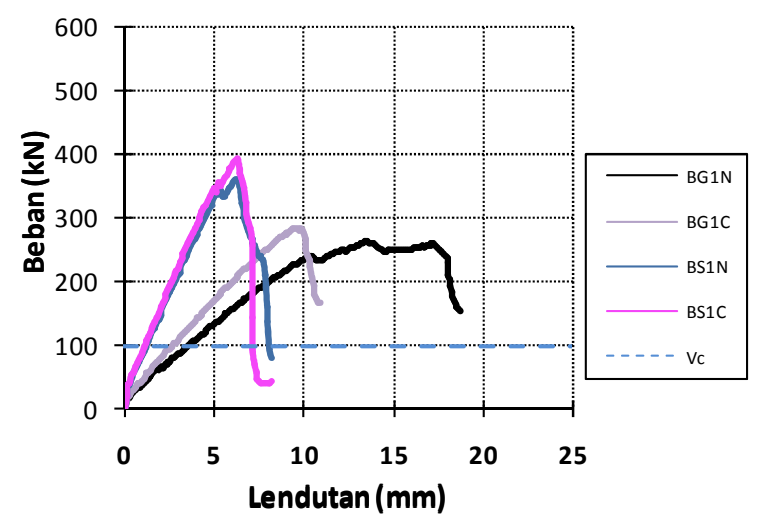

Gambar 4. Penggunaan Tulangan GFRP Meningkatkan Daktilitas Balok

Penambahan perkuatan dengan pelat CFRP secara langsung mempengaruhi tegangan pada tulangan tarik. Tegangan pada balok bertulangan baja dengan panjang penyaluran tambahan $100 \mathrm{~mm}$ yang diberi perkuatan CFRP mengalami penurunan sebesar $5.06 \%$. Selain itu dapat diketahui balok dengan panjang penyaluran 100mm mengalami keruntuhan akibat bond (Bond Failure). Dimana kapasitas bond dari balok sudah terlawati, kapisatas bond untuk tulangan baja dengan panjang penyaluran tambahan $100 \mathrm{~mm}$ adalah $200.332 \mathrm{kN}$ seperti yangterlihat pada Gambar 5(a).

Pada balok beton bertulang dengan panjang penyaluran tambahan $250 \mathrm{~mm}$, perkuatan dengan pelat CFRP meningkatkan kapasitas balok menahan beban sebesar $1.2 \%$, hal ini juga mempengaruhi tegangan tulangan tarik beton bertulang. Penambahan pelat CFRP tegangan tulangan tarik turun sebesar $6.7 \%$ seperti terlihat pada Gambar 5.(b). Perilaku berbeda ditunjukan oleh panjang penyaluran tambahan $250 \mathrm{~mm}$. untuk balok beton bertulang dengan dan tanpa perkuatan keruntuhan yang terjadi berupa keruntuhan geser. Hal ini terlihat pada Gambar 5.(b) bahwa kapasitas geser telah terlewati. Kapasitas geser beton $(\mathrm{Vc})$ adalah $99.734 \mathrm{kN}$ dan kapastitas bond untuk panjang penyaluran $250 \mathrm{~mm}$ dengan tulangan baja adalah $500.83 \mathrm{kN}$.

Analisis pada perilaku balok dengan tulangan GFRP yang diperkuat dengan pelat CFRP menunjukkan bahwa perkuatan dengan pelat CFRP secara langsung mempengaruhi tegangan pada tulangan tarik. Terlihat pada Gambar 5.(c) terjadi penurunan tegangan pada balok dengan perkuatan, yaitu sebesar $18.8 \%$. Selain berpengaruh pada kemapuan dan tegangan, balok dengan perkuatan pelat CFRP juga berkonstribusi terhadap penambahan kekakuan balok. Penambahan kekakuan pada balok deformasi besar dengan perkuatan pelat CFRP adalah sebesar $50.9 \%$

Balok beton betulangan GFRP dengan panjang penyaluran 100mm mengalami keruntuhan akibat bond (Bond Failure). Terlihat pada Gambar 5.(c) kapasitas bond dari balok sudah terlawati dimana kapisatas bond untuk tulangan GFRP dengan panjang penyaluran tambahan $100 \mathrm{~mm}$ adalah $168.461 \mathrm{kN}$. 


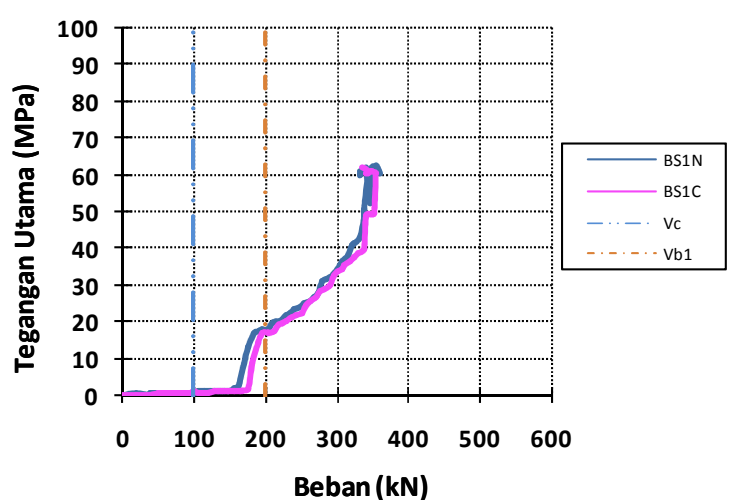

(a)

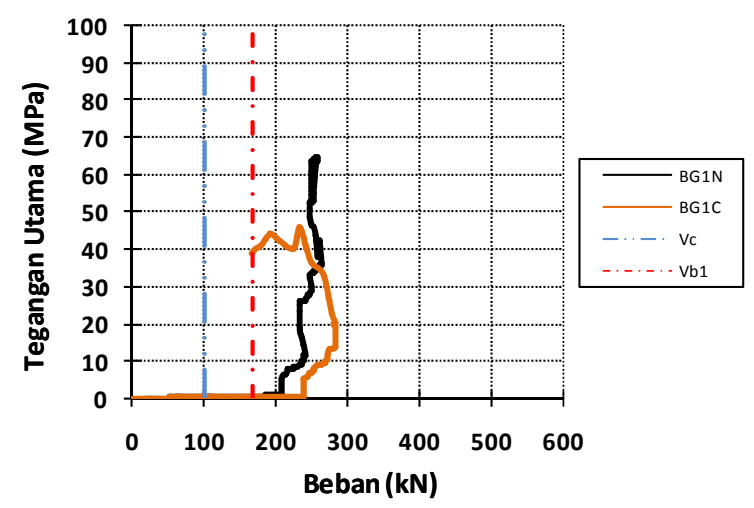

(c)

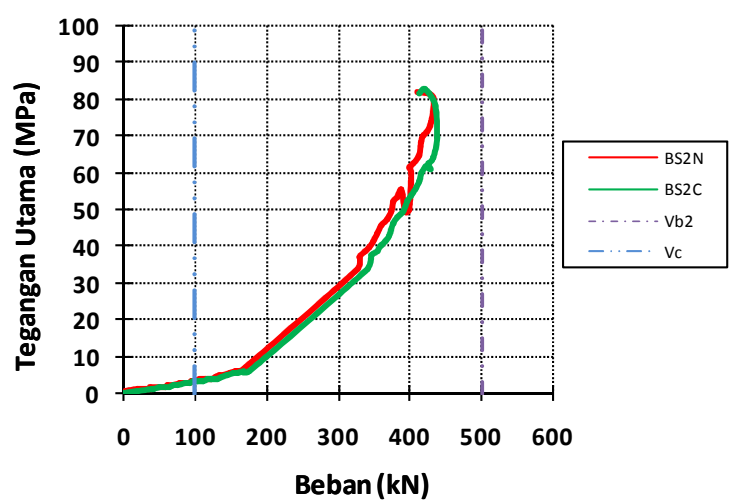

(b)

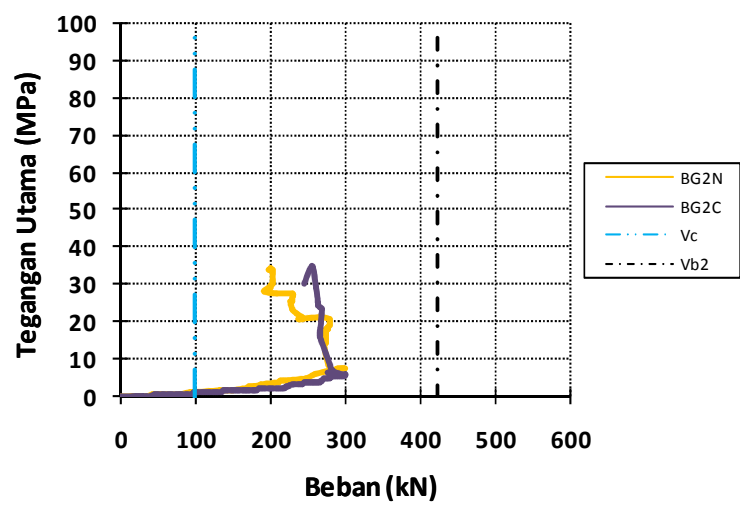

(d)

Gambar 5. Pengaruh Penambahan Perkuatan dengan Pelat CFRP Terhadap Tegangan Tulangan Tarik

Pada balok dengan deformasi besar dan panjang penyaluran tambahan $250 \mathrm{~mm}$ perkuatan dengan pelat CFRP mampu meningkatkan kekakuan dari balok beton bertulang tersebut sebesar $58.33 \%$ seperti terlihat pada Gambar 5.(d). sedangkan kapasitasnya hanya meningkat $0,8 \%$. Hal ini terjadi karena keruntuhan yang tejadi berupa keruntuhan geser hal ini terlihat bahwa beton telah melewati kapasitas gesernya namun belom melewati kapasitas bondnya. Kapasitas bond untuk balok tulangan GFRP dengan panjang penyaluran tambahan $250 \mathrm{~mm}$ adalah sebesar $421,152 \mathrm{kN}$. Perkuatan dengan pelat CFRP secara langsung mempengaruhi tegangan pada tulangan tarik. Terlihat pada Gambar 5.(d) terjadi penurunan tegangan pada balok dengan perkuatan, yaitu sebesar $7.3 \%$.

\section{KESIMPULAN}

Berdasarkan analisa dan pembahasan terhadap balok beton bertulang dengan perkuatan pelat CFRP dapat diambil kesimpulan sebagai berikut :

1. Pada balok dengan bentang geser yang pendek ( $\mathrm{a} / \mathrm{d} \square 2.5$ ) dan panjang penyaluran tambahan $100 \mathrm{~mm}$, pemasangan pelat CFRP dapat menaikkan kemampuan balok dalam memikul beban. Dengan tulangan baja meningkat sebesar $8.4 \%$ dan untuk tulangan GFRP penggunaan pelat CFRP menaikkan kemampuan menahan beban sebesar $7.8 \%$.

2. Pada balok dengan bentang geser yang pendek ( $\mathrm{a} / \mathrm{d} \square 2.5$ ) dan panjang penyaluran tambahan $250 \mathrm{~mm}$, pemasangan pelat CFRP dapat menaikkan kemampuan balok dalam memikul beban. Dengan tulangan baja meningkat sebesar $1.2 \%$ dan untuk tulangan GFRP penggunaan pelat CFRP menaikkan kemampuan menahan beban sebesar $0.8 \%$. 
3. Pada balok beton bertulang dengan panjang penyaluran $100 \mathrm{~mm}$ dan tulangan baja pemasangan pelat CFRP dapat mengurangi tegangan tulangan tarik di daerah perletakan sebesar $5.06 \%$ dan dengan tulangan GFRP sebesar $18.8 \%$.

4. Pada balok beton bertulang dengan panjang penyaluran $250 \mathrm{~mm}$ dan tulangan baja pemasangan pelat CFRP dapat mengurangi tegangan tulangan tarik di daerah perletakan sebesar $6.7 \%$ dan dengan tulangan GFRP sebesar $7.3 \%$.

\section{DAFTAR KEPUSTAKAAN}

Alami, F. "Perkuatan Lentur Balok Beton Bertulang dengan Glass Fiber Reinforced Polymer (GFRP)". Seminar dan pameran HAKI. 2010

American Concrete Institute 440.1R-06. "Guide for the Design and Construction of Structural Concrete Reinforced with FRP Bars" ACI Committee 440. 2006

American Concrete Institute 318M-08. "Building Code Requirements for Structural Concrete and Commentary" ACI Committee 318. 2008.

Baja Tulangan Beton (SII 0136-84)

Cervenka, V. Jendele, L. and Cervenka, J. "ATENA Program Documentation Part 1, Theory" Prague, February 23. 2011.

Jack,C .Cormac, MC. "Desain Beton Bertulang”. Erlangga, Jakarta. 2004.

Jensen, A, Chenoweth,H. "Kekuatan Bahan Terapan”. Erlangga, Jakarta. 1991

Larralde,J.and Rodriguez. Silva. "Bond and Slip of FRP Rebars in Concrete". Journal of Materials in Civil Engineering, Vol. 5, No.1. February, 1993

Morita, S. and Fujii, S. (1982), "Bond Capacity of Deformed Bars Due to Splitting of Surrounding Concrete", Bond in Concrete, edited by Bartos. P., Applied Science Publisher, pp. 331-341.

Paulay, T and R.Park. "Reinforced Concrete Structure". John Wiley \&Sons. Inc. United States of America. 1975

Sambowo. KA, Susilorini.MI. "Perencanaan Beton Bertulang Lanjutan, Daktilitas Balok Beton Bertulang". Surya Perdana Semesta, Semarang. 2010

S.J Fooster, N Khomwan. "Debonding Failure in CFRP Flexurally Strengthened Reinforced Concrete Beams". New South Wales University. 2005.

Teng,J.G, and S.T Smith . "FRP Strengthened RC Beams. I : Review of Debonding Strength Models". Hongkong Polytechnic University, Hongkong. 2001.

Teng,J.G, and S.T Smith . "FRP Strengthened RC Beams. II : Assement of Debonding Strength Models". Hongkong Polytechnic University, Hongkong. 2001.

Thamrin. R, Kaku. T. "Bond Behavior of CFRP Bars in Simply Supported Reinforced Concrete Beam with Hanging Region". Journal of Composites for Construction, Vol.11, No. 2, April 1, 2007.

Thamrin. R, Kaku. T, Komiya. I. "Studi of flexural and Bond Behavior of RC Beam with FRP rods". Proc os Ninth East Asia Pasific Conference on Structural Engineering and Construction. Bali-indonesia. 2003

Thamrin. R, "Petunjuk Penggunaan, Reinforced Concrete Cross Section Analysis (RCCSA)". Universitas Andalas, Padang. 2013

Vis, WC, R segel. "Perhitungan perencanaan sementara untuk beton bertulang". Stuvo, Nerderland. 1987 http://www.krakatauwajatama.co.id/index.php?option=com content\&view=article \&id=7\&Itemid=36 